
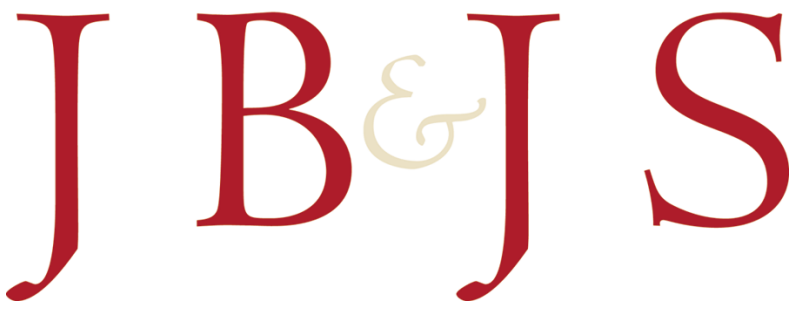

This is an enhanced PDF from The Journal of Bone and Joint Surgery

The PDF of the article you requested follows this cover page.

\title{
Interlocking Telescopic Rod for Patients with Osteogenesis Imperfecta
}

Tae-Joon Cho, In Ho Choi, Chin Youb Chung, Won Joon Yoo, Ki Seok Lee and Dong Yeon Lee J Bone Joint Surg Am. 2007;89:1028-1035. doi:10.2106/JBJS.F.00814

This information is current as of September 4, 2009

Supplementary material

Reprints and Permissions

Publisher Information
Commentary and Perspective, data tables, additional images, video clips and/or translated abstracts are available for this article. This information can be accessed at http://www.ejbjs.org/cgi/content/full/89/5/1028/DC1

Click here to order reprints or request permission to use material from this article, or locate the article citation on jbjs.org and click on the [Reprints and Permissions] link.

The Journal of Bone and Joint Surgery 20 Pickering Street, Needham, MA 02492-3157 www.jbjs.org 


\title{
Interlocking Telescopic Rod for Patients with Osteogenesis Imperfecta
}

\author{
By Tae-Joon Cho, MD, In Ho Choi, MD, Chin Youb Chung, MD, Won Joon Yoo, MD, \\ Ki Seok Lee, MD, and Dong Yeon Lee, MD \\ Investigation performed at the Department of Orthopaedic Surgery, Seoul National University Children's Hospital, Seoul, South Korea
}

\begin{abstract}
Background: Intramedullary fixation with use of a telescopic rod with a T-piece is one of the standard methods for long-bone stabilization in growing children with osteogenesis imperfecta. However, installation and removal of this device can cause substantial damage to the distal joint, which limits its use, especially in the tibia. We devised a modification of the telescopic rod system-the interlocking telescopic rod-in which the obturator is a simple rod with a hole, instead of a T-piece, at its distal end.
\end{abstract}

Methods: The clinical and radiographic outcomes were evaluated more than two years following treatment of thirtytwo limb segments (twenty-three tibiae and nine femora) with this new rod system in fifteen patients with osteogenesis imperfecta.

Results: All rods were inserted without an arthrotomy of the distal joint, and all telescoped successfully. The interlocking pin used in the first five limb segments backed out between five and thirty-three months postoperatively. A revised fixation technique was used in the remaining twenty-seven limb segments, and the interlocking pin had not backed out at an average 3.1 years postoperatively. Proximal migration of the obturator was observed in four tibiae after 2.5 years. The cumulative survival rate of the rod at four years postoperatively was $88.7 \%$.

Conclusions: Both insertion and removal of an interlocking telescopic rod are much less invasive than insertion and removal of a conventional telescopic rod with a T-piece anchor. The interlocking pin at the distal epiphysis provides effective anchorage for telescoping. Our interim results showed survival of the device to be comparable with, or better than, that of the conventional telescopic rod.

Level of Evidence: Therapeutic Level IV. See Instructions to Authors for a complete description of levels of evidence.

$\mathrm{T}$ he concept of multiple osteotomies and internal fixation with an intramedullary rod for deformity correction and prevention of long-bone fractures in patients with osteogenesis imperfecta was first described by Sofield and Millar in $1959^{1}$ and has been widely accepted. In 1963, Bailey and Dubow ${ }^{2}$ introduced an elongating rod system, whereby a hollow sleeve and an internal obturator were engaged and anchored by T-pieces at the proximal and distal epiphyses of the long bones. This design allowed telescoping elongation as the long bone grew at the physes, and effectively decreased the number and frequency of operations required in growing children ${ }^{3-8}$. However, its use was technically demand- ing, and high rates of operative and postoperative complications were reported ${ }^{6,9-15}$. The Sheffield telescopic rod was devised to eliminate problems associated with the T-piece ${ }^{10}$ but was nevertheless associated with other complications, such as intra-articular, metaphyseal, or extracortical rod migration. Injuries caused by the implantation of elongating rods with a T-piece are substantial but are rarely discussed. Insertion of the distal obturator is more invasive than is insertion of the proximal sleeve in both the femur and the tibia, as it requires an arthrotomy of the distal joint, which may damage the articular cartilage ${ }^{5,8}$. Installation of the obturator with a T-piece into the tibia is even more traumatic, requiring com-

Disclosure: The authors did not receive any outside funding or grants in support of their research for or preparation of this work. Neither they nor a member of their immediate families received payments or other benefits or a commitment or agreement to provide such benefits from a commercial entity. No commercial entity paid or directed, or agreed to pay or direct, any benefits to any research fund, foundation, division, center, clinical practice, or other charitable or nonprofit organization with which the authors, or a member of their immediate families, are affiliated or associated. 
The Journal of Bone \& JOINT SURGERY • JBIS.ORG VOlume 89-A · Number 5 - MAY 2007

plete dislocation of the ankle joint or a medial malleolar osteotomy ${ }^{5,8}$, possibly damaging the weight-bearing area of the distal tibial articular cartilage. These possible iatrogenic problems along with higher complication rates ${ }^{13,16}$ have made use of the telescopic rod in the tibia controversial, and as a result some authors prefer rods that do not elongate ${ }^{5,8}$.

We developed a new anchorage system to be used in the distal epiphysis to allow telescoping of an elongating rod. This system does not require arthrotomy for insertion of the obturator, and thus damage to ligaments and articular cartilage can be avoided. The system was originally devised for the tibia, but with accumulated experience its use was extended to the femur. The purposes of this study were to introduce this new design and to report the intermediate follow-up results of its use in patients with osteogenesis imperfecta.

\section{Materials and Methods Implant Design}

The interlocking telescopic rod is composed of a hollow sleeve and an internal obturator. The sleeves are of the same shape and dimension as those used in the telescopic intramedullary rod system (Sheffield Rod; Downs Surgical, Sheffield, England) ${ }^{10,17}$. The obturators (Dyna-Locking Telescopic Rod; U\&I, Gyeonggi, Korea) have the same diameters as those of the Sheffield rod system. The interlocking telescopic rod does not have a T-piece at the distal end but instead has a small hole that allows the placement of an interlocking pin (a Kirschner wire, with a threaded tip, of 1.4 $\mathrm{mm}$ in diameter [for 3, 4, and 5-mm-diameter sleeves] or 1.8 $\mathrm{mm}$ in diameter [for 6 and 8-mm-diameter sleeves]) (Fig. 1).
Interlocking Telescopic Rod For Patients

WITH OSTEOGENESIS IMPERFECTA

The obturators pass all of the way through the corresponding sleeves except for the 3-mm-diameter sleeve, for which the obturator has a widened distal tip to receive a $1.4-\mathrm{mm}$-diameter interlocking pin.

\section{Surgical Technique}

Preoperative radiographs are thoroughly evaluated to assess the deformity and to estimate the lengths and diameters of the rods to be used. However, for severely angulated limb segments, we determined the rod length intraoperatively, after performing multiple osteotomies.

The surgical procedure (Figs. 2-A and 2-B) consists of multilevel osteotomies performed to realign the limb segment along the rod. Percutaneous osteotomies ${ }^{8}$ are preferred, but open osteotomies are performed if intramedullary reaming is needed for a narrow or obliterated medullary cavity or resection of a substantial wedge of bone is needed to correct an acute angulation. A Kirschner wire is then inserted through the medullary canal of the osteotomy fragments. The sleeve is cut to an appropriate length and is inserted over the Kirschner wire in an antegrade direction. It is important to ensure that the distal tip of the sleeve points to the center of the distal epiphysis on both anteroposterior and lateral projections of radiographs. The Kirschner wire is then replaced with the obturator, which is advanced antegrade inside the sleeve into the distal epiphysis. The rotational orientation of the hole at its distal end can be controlled and adjusted with use of an obturator-impactor (Fig. 1). With use of a free-hand technique with fluoroscopic imaging, the obturator is then anchored in the distal epiphysis with a Kirschner wire. As the cortex of the

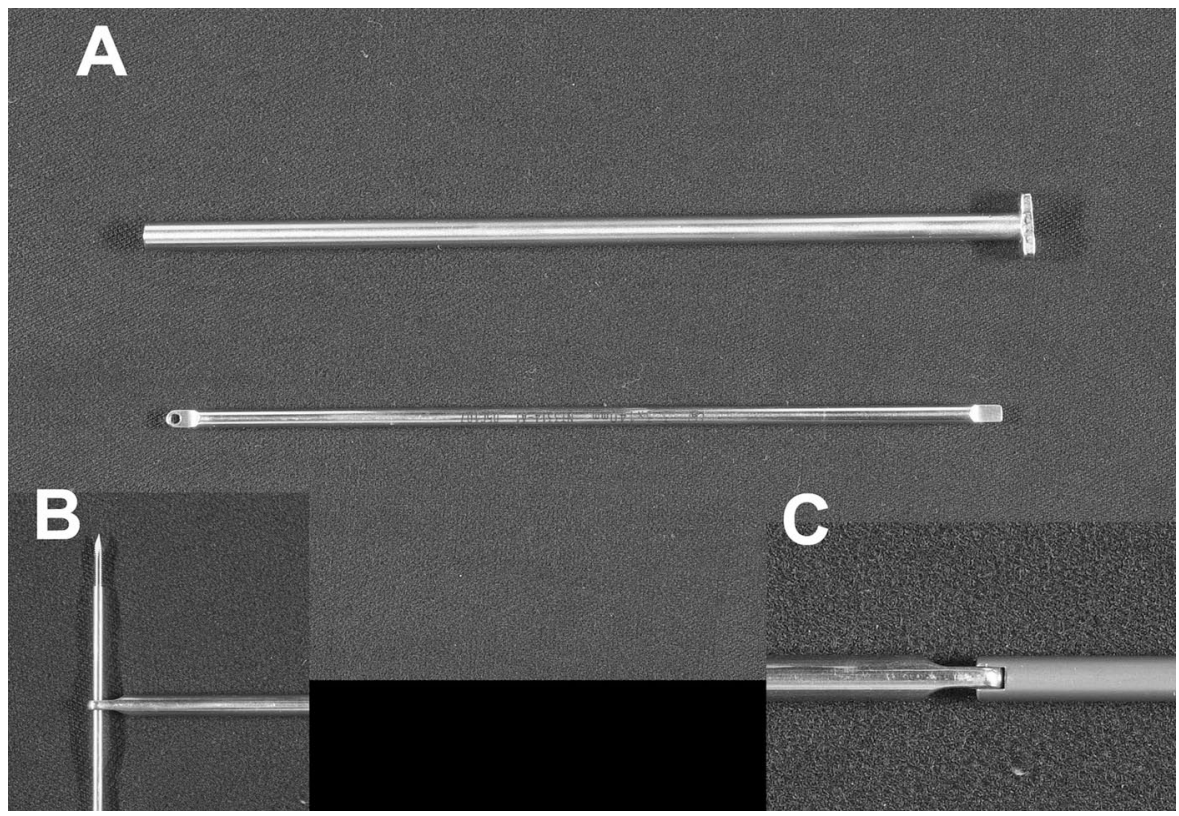

Fig. 1

The interlocking telescopic rod system. The hollow sleeve is the same as that used in the Sheffield telescopic rod system (A). The obturator has a hole at its distal tip to receive the interlocking pin (B). The flat proximal end can be fitted and assembled with a rotator-impactor (C). 
The Journal of Bone \& JOINT SURGERY • JBIS. ORG VOLUME 89-A · Number 5 - MAY 2007
Interlocking Telescopic Rod For Patients WITH OSTEOGENESIS IMPERFECTA
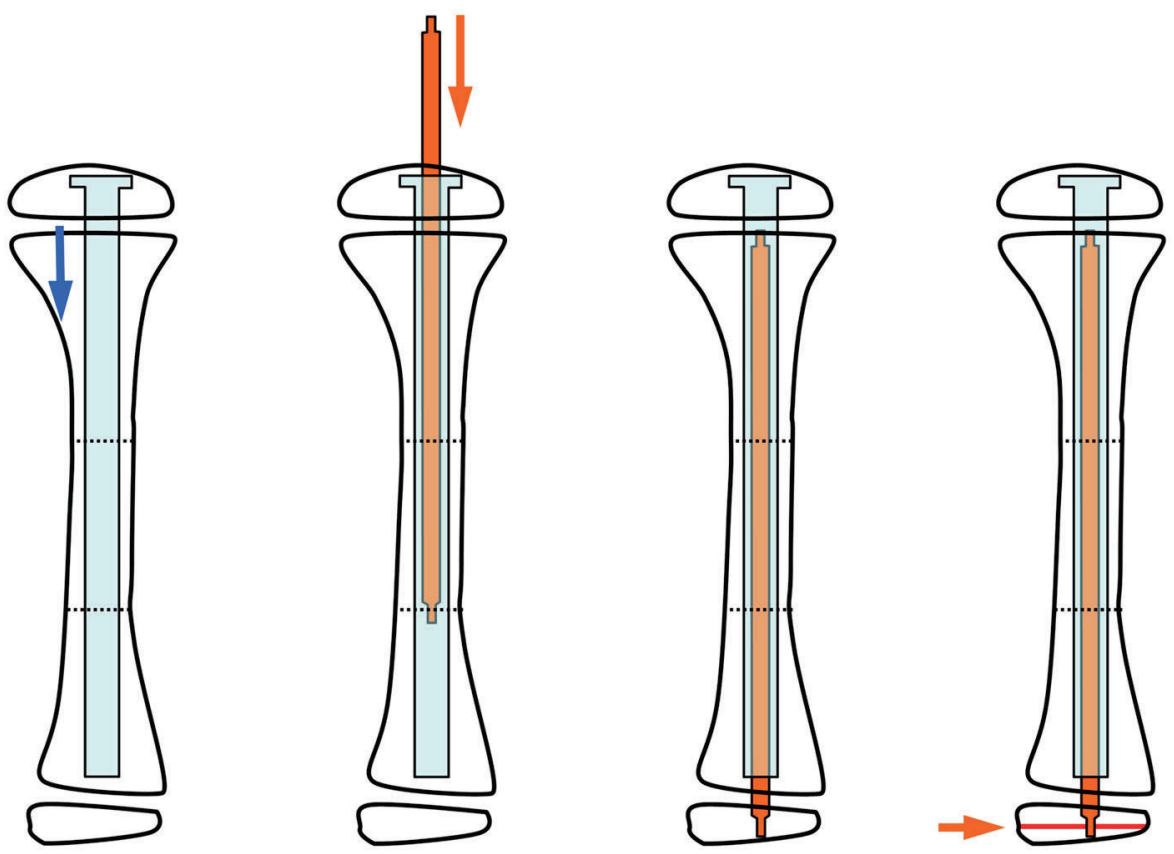

Fig. 2-A
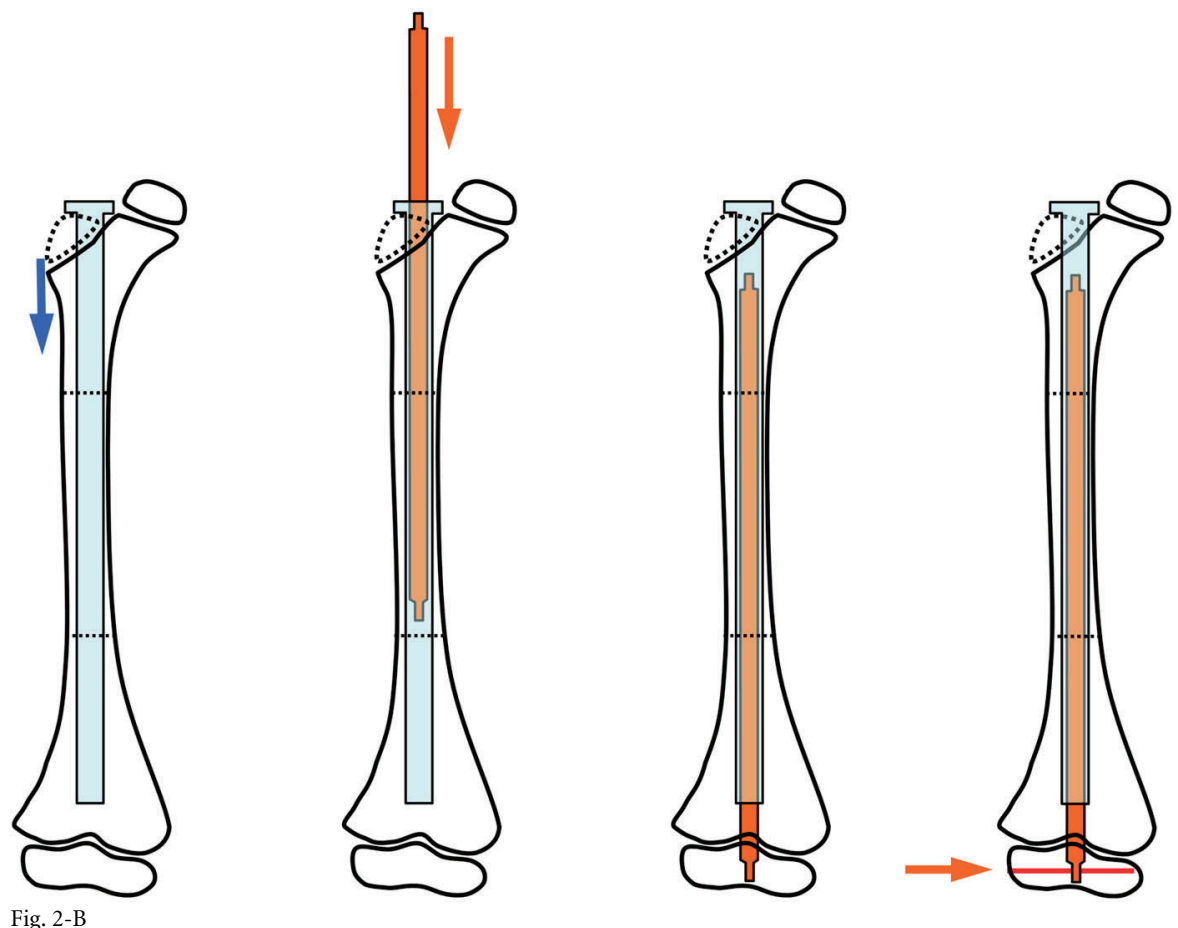

Schematic drawing of the surgical procedure for insertion of an interlocking telescopic rod in the tibia (Fig. 2-A) and the femur (Fig. 2-B). The obturator is inserted within the sleeve in an antegrade manner and is transfixed at the distal epiphysis. 
The Journal of Bone \& JOINT SURGERY · JBJS.org VOLUME 89-A · NUMBER 5 - MAY 2007
InTERlocking Telescopic Rod For Patients

WITH OSTEOGENESIS IMPERFECTA

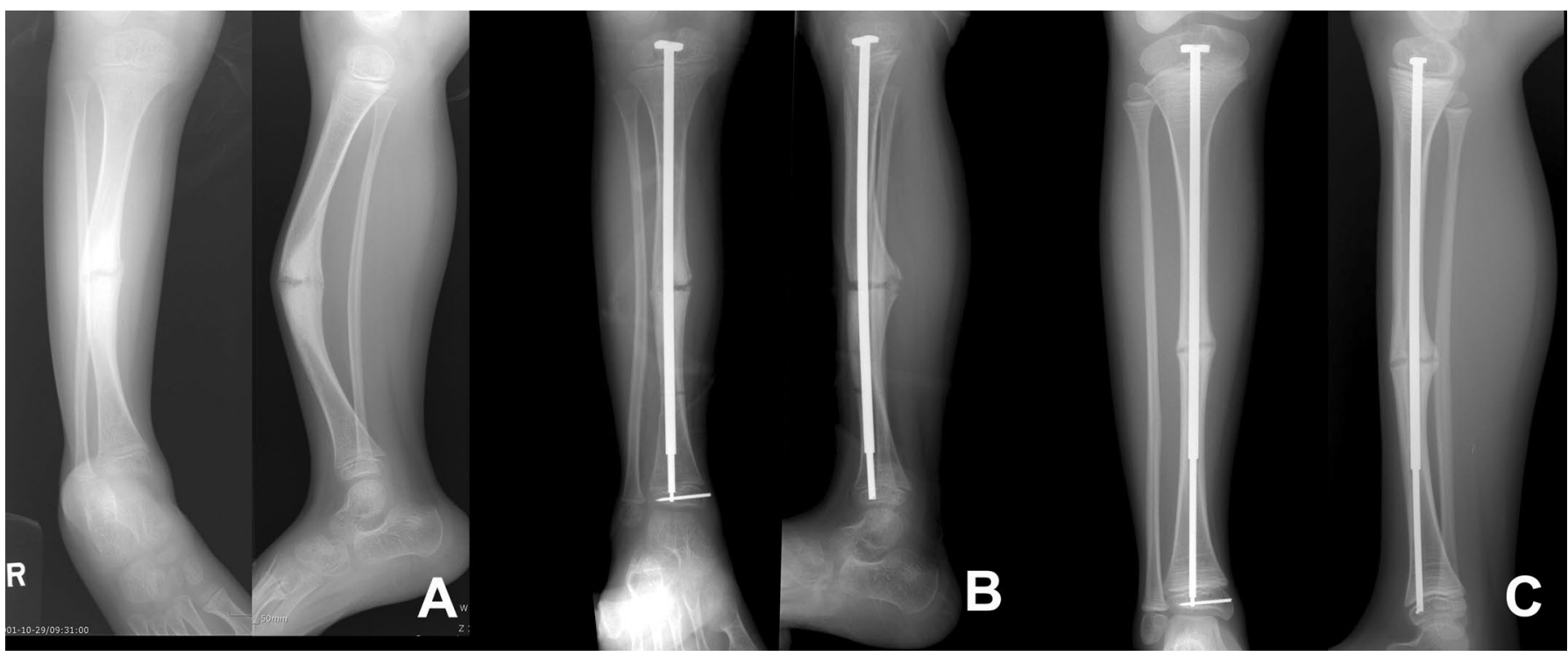

Fig. 3

Anteroposterior and lateral radiographs of the tibia of a five-year-old boy with type-IVB osteogenesis imperfecta. Marked angulation of the tibia (A) was corrected with use of an interlocking telescopic rod (B), which telescoped successfully for three years (C).

distal epiphysis is thin in patients with osteogenesis imperfecta, the Kirschner wire can be inserted manually and then advanced by gentle tapping. The wire is cut to an appropriate length and is pushed deep, preferably within the osseous epiphysis. Finally, in the femur, the sleeve position is adjusted so that the T-piece abuts the greater trochanter cartilage within the gluteal muscles. In the tibia, the T-piece of the sleeve is buried within the osseous epiphysis. In this series, it was rotated $90^{\circ}$ in ten cases as recommended by Marafioti and Westin $^{3}$, but it was placed only subchondrally to facilitate future rod replacement in thirteen cases.

In the case of the 3-mm sleeve, through which the obturator cannot pass because of its widened distal tip, the sleeve and obturator are assembled and then inserted as one piece through the osteotomy fragments. When the sleeve reaches its destination, the obturator is further advanced into the distal epiphysis and is transfixed with use of the technique described above.

All limbs are immobilized with a long leg splint for four to six weeks postoperatively.

\section{Patients and Evaluation}

This study was approved by our institutional review board, and the patients and/or their parents gave informed consent to participate. The first fifteen consecutive patients (seven girls and eight boys) with osteogenesis imperfecta who had undergone insertion of an interlocking telescopic rod into the femur or tibia and had been followed for more than two years after the index operation were included. Three patients had osteogenesis imperfecta type I according to the classification system of Sillence et al. ${ }^{18}$, three had type III, and nine had type IV.

Twenty-three tibiae and nine femora underwent surgery. The patient's age at the time of the surgery and the follow-up period were recorded separately for each operatively treated limb segment. The mean age at the time of the surgery was 7.3 years (range, 1.9 to 11.9 years), and the mean duration of follow-up was 3.3 years (range, 2.0 to 6.9 years). Follow-up was considered to be complete when any part of the rod system was removed or when skeletal maturity was reached. All patients received a bisphosphonate, either oral alendronate or cyclic intravenous pamidronate, before and after the index operations. The patients were examined clinically every three to six months, and radiographs were made every six to twelve months. The fracture history and complications were recorded.

Survival analysis with the Kaplan-Meier method was performed with use of SPSS for Windows software (version 12.0; SPSS, Chicago, Illinois). In the calculation of surgeryfree survival, any additional surgical intervention such as removal or replacement of the interlocking telescopic rod, advancement of the proximally migrated sleeve, or adjustment of the interlocking pin was defined as the end point. In the calculation of rod survival, the end point was defined as removal or replacement of the rod due to a complication. As long as a rod remained in the operatively treated limb segment, regardless of whether it was elongating, it was considered to have not reached the end point.

\section{Results}

$A$ pplication of the intramedullary rod and the interlocking $\mathrm{A}_{\text {pin fixation were performed successfully in all limb seg- }}$ ments, and telescoping took place uneventfully in all of the segments for at least eighteen months (Figs. 3 and 4).

Five operatively treated limb segments sustained a fracture postoperatively: one femur showed a stress fracture, and the other femur and the three tibiae sustained a linear fracture 
The Journal of Bone \& JOINT SURGERY • JBIS.ORG VOLUME 89-A · NUMBER 5 - MAY 2007
INTERLOCKING TELESCOPIC ROD FOR PATIENTS

WITH OSTEOGENESIS IMPERFECTA

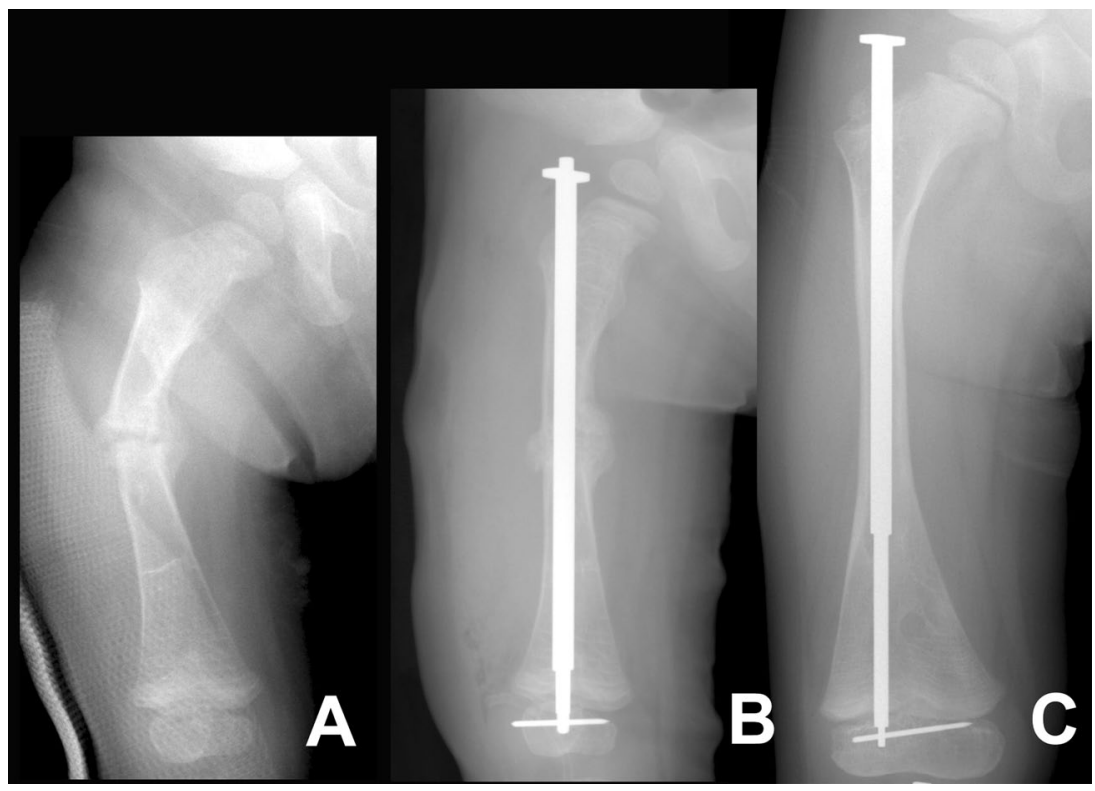

Fig. 4

Anteroposterior radiographs of the femur of a two-year-old girl with type-III osteogenesis imperfecta. She sustained a femoral shaft fracture $(A)$, which was fixed with an interlocking telescopic rod (B). The rod telescoped successfully for 2.3 years (C).

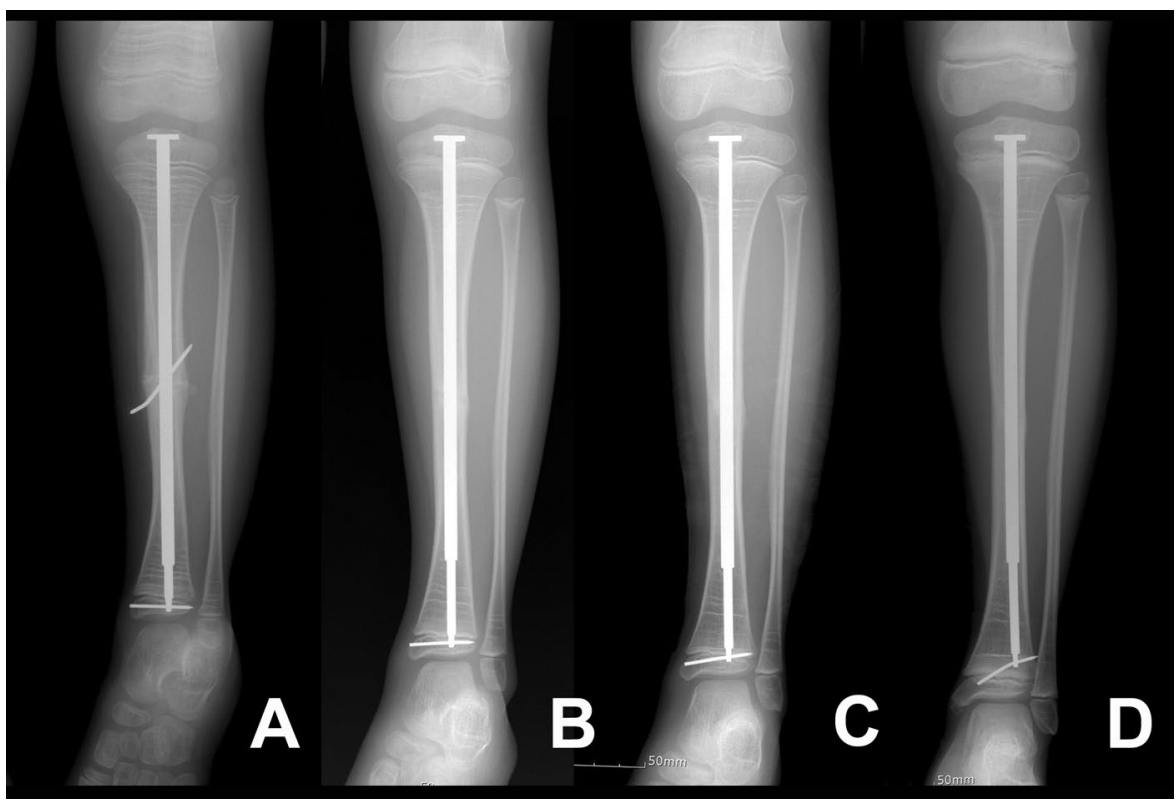

Fig. 5

Anteroposterior radiographs of the tibia of a 4.5-year-old girl with type-IVA osteogenesis imperfecta. Repeated tibial shaft fractures were treated with use of an interlocking telescopic rod. Radiographs made at one month (A), 1.5 years (B), two years (C), and three years (D) showed proximal migration of the obturator with the interlocking pin cutting through the physis, although no obvious physeal closure was detected at this site. The interlocking telescopic rod eventually functioned as a non-elongating rod.

following minor trauma. All healed uneventfully after a brief period of immobilization with a splint.

In one tibia, in which the interlocking pin had been placed eccentrically at the anterior part of the distal epiphysis, the rod cut through the anterior cortex of the distal part of the tibia. Gradual anterior angulation at the distal part of the tibia resulted in the need for a closing anterior wedge osteotomy and insertion of another interlocking telescopic rod four years postoperatively. Proximal migration of the sleeve was observed in two limb segments. One tibial sleeve, which had 
The Journal of Bone \& JOINT SURGERY • JBJS.org VOLUme 89-A · Number $5 \cdot$ MAY 2007
Interlocking Telescopic Rod for Patients WITH OSTEOGENESIS IMPERFECTA

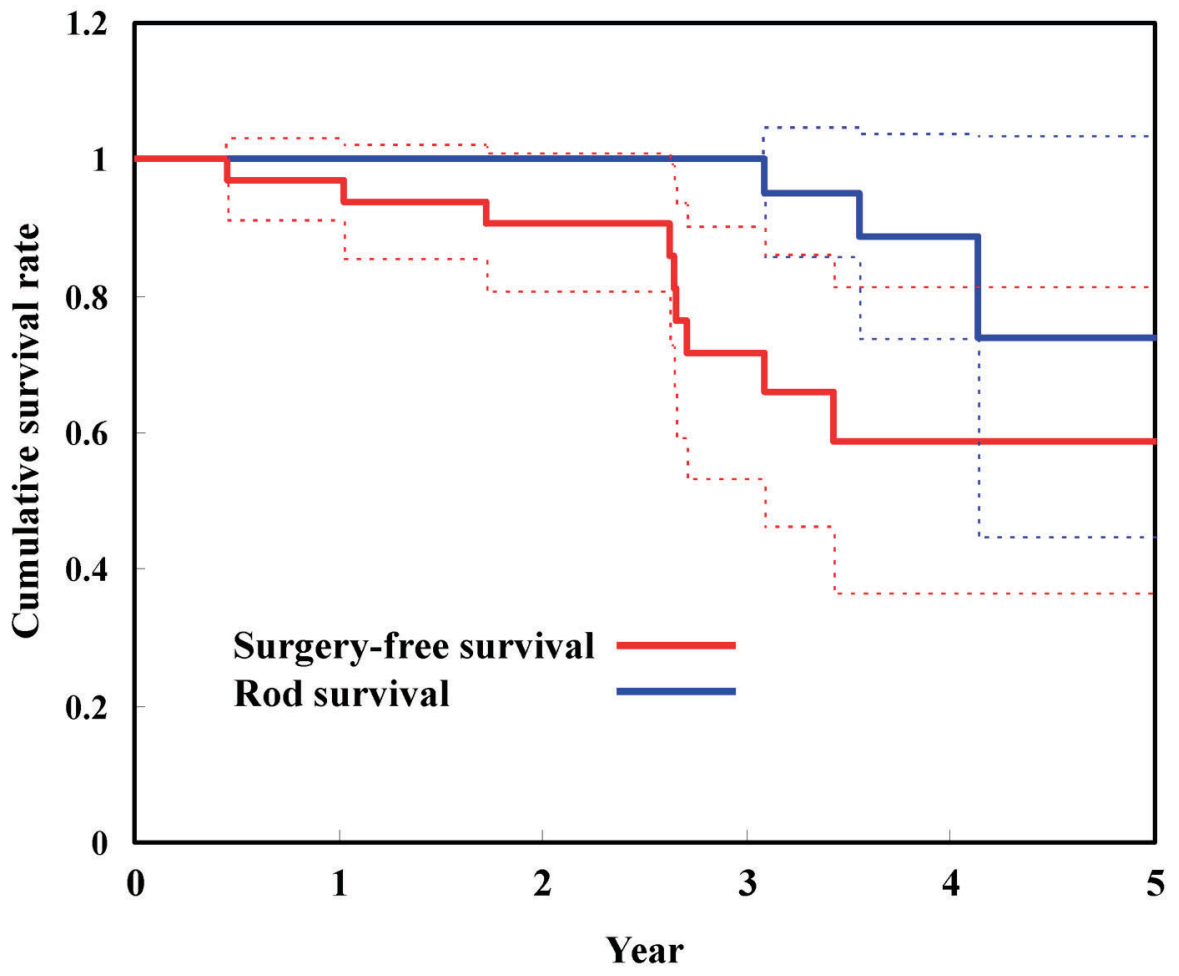

Fig. 6

Survival curves for the interlocking telescopic rod. The end point of surgery-free survival was any surgical intervention after the installation of the interlocking telescopic rod. The end point of rod survival was removal or replacement of the rod due to any complication. The dotted lines represent the $95 \%$ confidence intervals.

been implanted subchondrally, migrated proximally into the knee joint. It was repositioned through a small arthrotomy and then remained subcortical for the next two years. One femoral sleeve migrated proximally and was relocated and tied to the proximal part of the femur with a wire.

At the time of the latest follow-up, seven patients could walk without limitation, six could walk a short distance without a walking aid but required an aid for long distances, one required a walking aid at all times, and one could stand and walk only during rehabilitation sessions.

Backing out of the interlocking pin was observed, at five to thirty-three months postoperatively, in the first four tibiae and the first femur treated in this series. In these five cases, a smooth Kirschner wire had been used as the interlocking pin. In three of the tibiae, the backed-out interlocking pin was removed, allowing the rod to function as a non-elongating rod. One of these patients reached skeletal maturity without the development of any angulation or fracture of the tibia, whereas the other two patients underwent removal of the rod to treat progressive tibial angulation at the tip of the rod or osteomyelitis. In the remaining two cases, the interlocking pin was replaced with a pin with a threaded tip, which was inserted deep into the epiphysis, as soon as backing out was detected. The new pin did not back out in either of the two cases, which were followed for three and four years. None of the twenty-seven limb segments in which a Kirschner wire with a threaded tip had been used initially had backing out at the time of follow-up, at an average of 3.1 years.

Proximal migration of the obturator with the interlocking pin cutting through the physis was observed in four tibiae in two patients. Both had Sillence type-IVA osteogenesis imperfecta, and they underwent the index operation at the ages of three and 4.5 years. The proximal migration was detected at 2.5 and three years postoperatively, as the rods failed to telescope even though they appeared straight. In one patient, both interlocking pins were repositioned within the distal epiphysis, after which the sleeves started to migrate distally. In the second patient, no additional surgery was done and the intramedullary rods functioned as non-elongating rods (Fig. 5).

Twenty-three $(72 \%)$ of the thirty-two rods telescoped for an average of 2.8 years without any complications. The cumulative surgery-free survival rate of the rods was $90.6 \%$ (95\% confidence interval, $80.5 \%$ to $100.7 \%$ ) at two years, $71.6 \%$ (95\% confidence interval, $53.1 \%$ to $90.0 \%$ ) at three years, and $58.7 \%$ (95\% confidence interval, $36.4 \%$ to $81.0 \%$ ) at four years (Fig. 6). The rod had to be removed or replaced in only three cases. The cumulative survival rate of the rod itself was $88.7 \%$ (95\% confidence interval, $73.7 \%$ to $103.6 \%$ ) at four years (Fig. 6). 
ThE JOURNAL OF BONE \& JOINT SURGERY · JBJS.ORG VOlume 89-A - NUmber 5 - MAY 2007
Interlocking Telescopic Rod For Patients WITH OSTEOGENESIS IMPERFECTA

\section{Discussion}

U ultiple osteotomies with intramedullary fixation are the 1 mainstay of treatment of the long bones of growing children with osteogenesis imperfecta. We believe that the use of an elongating rod is beneficial in patients with substantial remaining growth. However, the Bailey-Dubow elongating nail has been associated with a high complication rate, particularly related to the T-piece ${ }^{6,9-15}$. The Sheffield telescopic rod system, a modification of the Bailey-Dubow nail, eliminated T-piece-related complications by permanently fixing the Tpiece to the sleeve $\mathrm{e}^{10,17}$, but it shares the problems of traumatic insertion and rod migration with its predecessor ${ }^{19,20}$.

Placement of an obturator with a T-piece at the distal fragment is an invasive procedure, especially in the tibia. It requires almost complete dislocation of the ankle joint with use of either extensive division of the deltoid ligament or medial malleolar osteotomy $y^{7,11,17,19,20}$. Also, the T-piece has to be inserted through the weight-bearing surface of the distal tibial articular cartilage, which leaves a large scar in a relatively narrow area. Some authors ${ }^{3,9,20}$ have reported no functional change of the ankle joint after ankle arthrotomy, but damaged articular cartilage and subsequent fibrocartilaginous healing are highly likely to have a detrimental effect on the ankle joint in the long run, especially in patients who can walk. Therefore, installation of the telescopic rod with a Tpiece remains controversial for tibial bones ${ }^{8}$.

Janus et al. ${ }^{15}$ described a modification of the Sheffield rod system for the tibia in which a prebent obturator was anchored at the medial malleolus, eliminating the need for an arthrotomy of the ankle joint. However, ankle valgus deformity due to an inadequately prebent obturator was observed in some cases. With use of the interlocking telescopic rod reported on here, not only can ankle joint arthrotomy and damage to the distal tibial articular cartilage be avoided, but accurate anatomic alignment of the tibia can be restored.

Another problem associated with distal tibial fixation is that often the distal tibial epiphysis in patients with osteogenesis imperfecta is hypoplastic compared with the proximal epiphysis. As the distal fixation pin of the interlocking telescopic rod is thinner than the T-piece, the interlocking telescopic rod can be used in younger children. In the current series, the youngest patient treated with a tibial interlocking telescopic rod was 3.2 years old.

It is not uncommon for patients with osteogenesis imperfecta to require revision surgery as they age. Sometimes an obturator with a T-piece is impossible to remove without causing serious damage to the joint or surrounding tissue ${ }^{7}$. In the interlocking telescopic rod system, the obturator can be converted into a smooth rod simply by removing the interlocking pin. Then the obturator can be easily removed through the diaphyseal medullary cavity or through the articular cartilage with minimal injury.

The concept of interlocking the telescopic rod at the distal part of the tibia is not new. Bailey ${ }^{4}$ reported a case in which the sleeve was placed distally and then transfixed with use of a cross-wire passed through the epiphysis. However, this configuration failed as the interlocking pin backed out. The smooth interlocking pins that we used initially, in the first four tibiae and the first femur that we treated, backed out, but this problem was overcome by using a Kirschner wire with a threaded tip and inserting it deep into the chondroepiphysis.

Failure of telescoping and subsequent intramedullary migration of the rod have been reported in several clinical series $^{6,7,9-11,13-16,20}$. A telescopic rod elongates only when the forces generated by proximal and distal fixation points exceed the friction forces between the sleeve and the obturator and between the hardware and the surrounding tissue. However, there appears to be a gray zone since, although the rod appears straight and continues to telescope to some extent, the fixation end of the device may cut through the physis (Fig. 5). Karbowski et al. reported that the tibia has a higher rate of this complication than does the femur and that cutting through by the T-piece occurs more frequently at the distal part of the tibia ${ }^{16}$. We believe that the interlocking pin used with the interlocking telescopic rod, if properly implanted, provides stronger anchorage than does a T-piece. However, the obturator migrated proximally along with its interlocking pin in four of our thirty-two cases. If this complication occurs, we recommend no additional surgery; instead, we believe that the implant should be allowed to function as a non-elongating rod. Revision surgery is indicated only if substantial angulation, symptomatic anterior cortical cutting through, or a fracture developed at the tip of the outgrown rod.

All patients in the present series received bisphosphonate therapy for varying periods to strengthen the cortical bone and thereby prevent gradual angulation of the diaphysis, which helped to minimize the chance of the telescoping failing. However, the bisphosphonate may not have contributed appreciably to the strength of the distal fixation because additional bone formation on the epiphyseal side is less apparent than on the metaphyseal side ${ }^{21}$.

It is difficult to compare the survival of the interlocking telescopic rod with that of previously described telescopic rods because all series differ in terms of the definitions of complications or failure, surgical procedures used for insertion, and patient profiles. Marafioti and Westin $^{3}$ reported that the three-year rate of survival of the elongating rods in their series was $77 \%$. In our series, all of the rods survived for three years postoperatively, and the four-year survival rate was $89 \%$.

In summary, we described a new telescopic intramedullary rod system that does not cause injury to the distal articular cartilage of the long bones and that anchors the obturator to the distal epiphysis. The interlocking telescopic rod also appears to be easier to remove, with less trauma, during revision surgery. Our interim results show survivorship comparable with, or better than, that reported for a telescopic rod with a T-piece. Long-term follow-up until skeletal maturity or longer will be necessary to fully evaluate the benefits and limitations of this system. 
The Journal of Bone \& JoINT SURGERY · JBJS.ORG VOlume 89-A - NUmber 5 - MAY 2007
Interlocking Telescopic Rod For Patients WITH OSTEOGENESIS IMPERFECTA
Tae-Joon Cho, MD

In Ho Choi, MD

Won Joon Yoo, MD

Ki Seok Lee, MD

Dong Yeon Lee, MD

Department of Orthopaedic Surgery, Seoul National University

Hospital, 28 Yeongeon-dong, Jongno-gu, Seoul 110-744, South
Korea. E-mail address for I.H. Choi: inhoc@snu.ac.kr

Chin Youb Chung, MD

Department of Orthopaedic Surgery, Seoul National University Bundang Hospital, 300 Gumi-dong, Bundang-gu, Seongnam-si, Gyeonggi-do, 463-707, South Korea

\section{References}

1. Sofield HA, Millar EA. Fragmentation, realignment, and intramedullary rod fixation of deformities of the long bones in children. A ten-year appraisal. J Bone Joint Surg Am. 1959;41:1371-91.

2. Bailey RW, Dubow HI. Studies of longitudinal bone growth resulting in an extensible nail. Surg Forum. 1963;14:455-8.

3. Marafioti RL, Westin GW. Elongating intramedullary rods in the treatment of osteogenesis imperfecta. J Bone Joint Surg Am. 1977;59:467-72.

4. Bailey RW. Further clinical experience with the extensible nail. Clin Orthop Relat Res. 1981;159:171-6.

5. Niemann KM. Surgical treatment of the tibia in osteogenesis imperfecta. Clin Orthop Relat Res. 1981;159:134-40.

6. Gamble JG, Strudwick WJ, Rinsky LA, Bleck EE. Complications of intramedullary rods in osteogenesis imperfecta: Bailey-Dubow rods versus nonelongating rods. J Pediatr Orthop. 1988;8:645-9.

7. Mulpuri K, Joseph B. Intramedullary rodding in osteogenesis imperfecta. J Pediatr Orthop. 2000;20:267-73.

8. Zeitlin L, Fassier F, Glorieux FH. Modern approach to children with osteogenesis imperfecta. J Pediatr Orthop B. 2003;12:77-87.

9. Lang-Stevenson AI, Sharrard WJ. Intramedullary rodding with Bailey-Dubow extensible rods in osteogenesis imperfecta. An interim report of results and complications. J Bone Joint Surg Br. 1984;66:227-32.

10. Stockley I, Bell MJ, Sharrard WJ. The role of expanding intramedullary rods in osteogenesis imperfecta. J Bone Joint Surg Br. 1989;71:422-7.

11. Nicholas RW, James $P$. Telescoping intramedullary stabilization of the lower extremities for severe osteogenesis imperfecta. J Pediatr Orthop. 1990;10:219-23.

12. Porat S, Heller E, Seidman DS, Meyer S. Functional results of operation in os- teogenesis imperfecta: elongating and nonelongating rods. J Pediatr Orthop. 1991;11:200-3.

13. Zionts LE, Ebramzadeh E, Stott NS. Complications in the use of the BaileyDubow extensible nail. Clin Orthop Relat Res. 1998;348:186-95.

14. Jerosch J, Mazzotti I, Tomasevic M. Complications after treatment of patients with osteogenesis imperfecta with a Bailey-Dubow rod. Arch Orthop Trauma Surg. 1998;117:240-5.

15. Janus GJ, Vanpaemel LA, Engelbert RH, Pruijs HE. Complications of the Bailey-Dubow elongating nail in osteogenesis imperfecta: 34 children with 110 nails. J Pediatr Orthop B. 1999;8:203-7.

16. Karbowski A, Schwitalle M, Brenner R, Lehmann H, Pontz B, Worsdorfer O. Experience with Bailey-Dubow rodding in children with osteogenesis imperfecta. Eur J Pediatr Surg. 2000;10:119-24.

17. Wilkinson JM, Scott BW, Clarke AM, Bell MJ. Surgical stabilisation of the lower limb in osteogenesis imperfecta using the Sheffield Telescopic Intramedullary Rod System. J Bone Joint Surg Br. 1998;80:999-1004.

18. Sillence DO, Senn A, Danks DM. Genetic heterogeneity in osteogenesis imperfecta. J Med Genet. 1979;16:101-16.

19. Finidori G, Rigault P, Padovani JP, Bensahel H. L'enclouage centro-médullaire télescopique chez l'enfant atteint d'ostéogenèse imparfaite. [Expanding intramedullary rods in the treatment of osteogenesis imperfecta (author's transl)] Rev Chir Orthop Reparatrice Appar Mot. 1979;65:235-42. French.

20. Luhmann SJ, Sheridan JJ, Capelli AM, Schoenecker PL. Management of lower-extremity deformities in osteogenesis imperfecta with extensible intramedullary rod technique: a 20-year experience. J Pediatr Orthop. 1998;18:88-94.

21. Rauch F, Travers R, Munns $C$, Glorieux FH. Sclerotic metaphyseal lines in a child treated with pamidronate: histomorphometric analysis. J Bone Miner Res. 2004;19:1191-3. 